\title{
Multiple Gastrointestinal Vascular Variations in a Male Cadaver: A Case Report and Literature Review of Embryonic, Genetic, and Clinicosurgical Implications of Pathogenicity
}

\author{
Adegbenro Omotuyi John Fakoya ${ }^{1 *}$, Luis Manuel Pérez-Portocarrero², Yulia Kungurova ${ }^{2}$, Mariana Ndrio ${ }^{2}$, Xiomara Marty-Ramírez $^{2}$, \\ Derek Mizael Rodríguez-Piñero², Luis Eduardo Rentas-Figueroa ${ }^{2}$, Nahu Gulelat Dimitri², Juan Manuel Collazo-Román², \\ Graham Robert Dempsey-Corbett ${ }^{2}$, Abayomi Gbolahan Afolabi ${ }^{1}$, Thomas McCracken ${ }^{1}$, David Otohinoyi ${ }^{3}$ \\ ${ }^{1}$ Department of Anatomy, University of Medicine and Health Sciences, Basseterre, St. Kitts and Nevis; ${ }^{2}$ Medical Student, \\ University of Medicine and Health Sciences, Basseterre, St. Kitts and Nevis; ${ }^{3}$ Department of Research, All Saints University, \\ College of Medicine, Saint Vincent and Grenadines
}

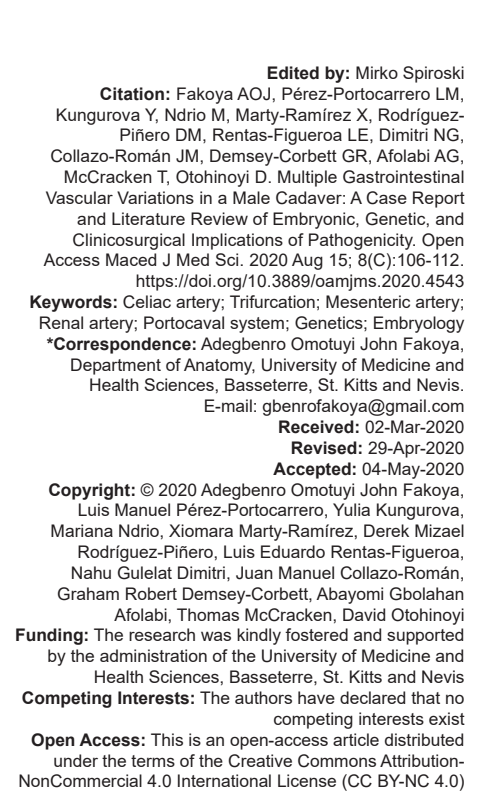

Abstract

BACKGROUND: To be acquainted with gastrointestinal vasculature variations is of utmost importance for establishing proper surgical management, improving safety, and decreasing the frequency of iatrogenic errors or complications arising in operational and post-operational settings.

CASE REPORT: The subject of the present publication involves a unique case of an 80-year-old Caucasian male who presented with various vascular variations during routine cadaveric dissection. Key variations presented in this report include unique findings such as an abnormal trifurcation of the celiac trunk, a bifurcation of the superior mesenteric artery, and its associated branches; an unusual portocaval system communication; and various rena variations. These variations are examined in an anatomical and clinical context. We further discuss the possible embryologic and genetic mechanisms which may lead to such vascular abnormalities

CONCLUSION: Furthermore, with this report, we aim to demonstrate the strong need for adequate knowledge of vascular variations as well as the important role of pre-operative imaging in the identification of vascular variations and the elimination of iatrogenic errors during surgical procedures.

\section{Introduction}

The knowledge of anatomical variations of vessels from the descending aorta provides essential information when it comes to planning and performing surgical and interventional procedures, especially those focused on the gastrointestinal (GI) system [1]. Just after crossing the diaphragmatic hiatus at the level of the $12^{\text {th }}$ thoracic vertebrae, the abdominal aorta extends ventrally and gives its first branch, known as the celiac artery or celiac trunk (CT) which supplies the foregut, pancreas, spleen, gallbladder, and the liver. This is possible because it trifurcates into the left gastric artery, splenic artery, and common hepatic artery in $89 \%$ of cases [2].
The abdominal aorta continues caudally, giving off its second branch known as the superior mesenteric artery (SMA), which arises ventrally to the level of the $1^{\text {st }}$ lumbar vertebrae, supplying blood to the derivatives of the midgut [3]. Around the next vertebrae ( $2^{\text {nd }}$ lumbar), we usually find the renal vasculature emerging lateral to the abdominal aorta and inferior vena cava. The descending aorta continues its way supplying the reminder of structures in the trunk and bifurcates into the lower extremities [3].

Variations arising during developmental stages are commonly found, which may lead to differences in the vascular architecture of the abdominal cavity. For example, reports have presented evidence of a communicating arterial branch between the CT and the SMA [4]. Others have described very unusual patterns 
( $<2 \%$ of the cases), such as the bifurcation of the CT into the splenic and left gastric artery, where the common hepatic artery appears directly from the aorta [5]. The most common renal variation is the presence of an accessory renal artery (RA), which usually arises between T11 and L4 and gives blood supply to the upper or lower renal poles [5]. Data suggest that the prevalence of variations between the CT and hepatic arteries is correlated with people with accessory renal arteries [6]. Therefore, there is a genetic component that orchestrates this unusual pattern in a minority of the population [3]

In general, there is a need to fully understand human anatomy from a rational and clinical perspective. In our study, we present a unique case of branching of the SMA involving the common hepatic artery and the blood supply to the small intestine as well as abnormalities in the renal vasculature.

\section{Case Presentation}

\section{Unique trifurcation of CT}

Upon routine cadaveric dissection at the University of Medicine and Health Sciences, St. Kitts, abdominal exploration of an 80-year-old Caucasian male showed evidence of vascular variations. Abdominal exploration of an 80-year-old Caucasian male showed evidence of vascular variations. Once the CT was identified as a visceral unpaired branch of the aorta at the level of T12, it revealed an unusual trifurcation. Normally, the three branches of the CT are left gastric artery, splenic artery, and common hepatic artery [7]. This dissection showed the normal anatomic course of the left gastric artery and splenic artery after branching from the CT, nevertheless, the third branch was identified as the inferior phrenic artery (IPA) which is normally found as a parietal branch of the abdominal aorta at the level of T12 (Figure 1).

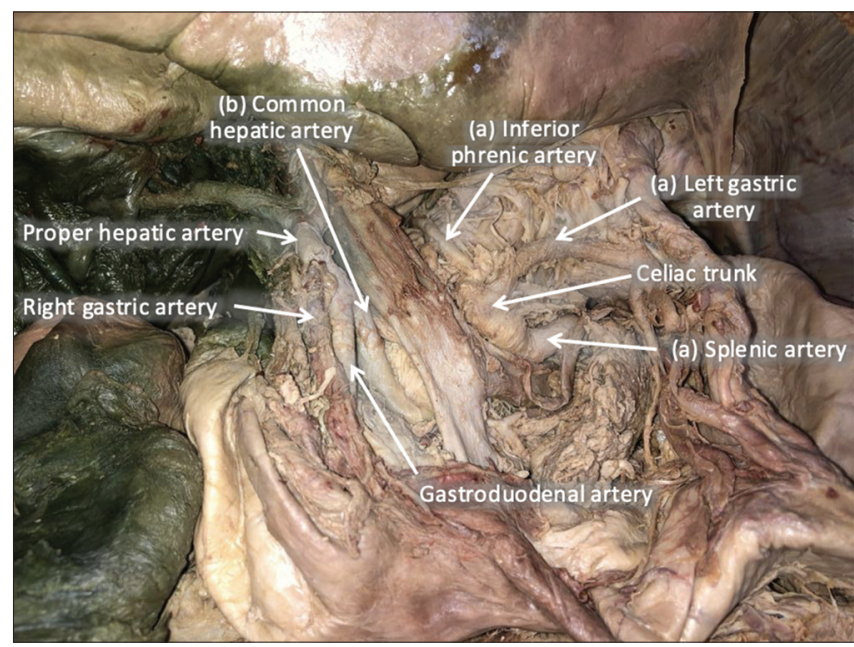

Figure 1: (a) Trifurcation of celiac trunk: left gastric artery, splenic artery, and inferior phrenic artery. (b) Common hepatic artery arising from the superior mesenteric artery.
To find the common hepatic artery, the left and right hepatic arteries were traced back until the beginning of its bifurcation to expose the proper hepatic artery, which normally is a branch of the common hepatic artery as well as the gastroduodenal artery [8]. After exposing the common hepatic artery, we traced it back to find that it branched from the SMA. In general, the branches of the SMA are the inferior pancreaticoduodenal arteries, middle colic artery, right colic artery, ileocolic artery, and jejunal and ileal arteries, which supply the large intestine [9].

\section{Bifurcation of the SMA}

Continuing with the dissection along the abdominal aorta, we found this case featured two SMA: SMA-1 and SMA-2 (Figure 2). SMA-2 branches from the ventral surface of the abdominal aorta at the level of the first lumbar vertebrae and first forms the superior pancreaticoduodenal artery, followed by the common hepatic artery (Figure 2). The SMA bifurcated over the left renal vein (LRV) prior. As seen in Figure 2, SMA-1 branched from the distal surface of SMA-2, where it began to supply the vasculature of the proximal midgut - the inferior pancreaticoduodenal artery and proximal jejunal artery branches. Supplying the distal midgut, SMA-2 uncharacteristically provided branching of the common hepatic before it continued to branch into the middle colic artery, right colic artery, ileocolic artery, ileal arteries, and additional jejunal branches.

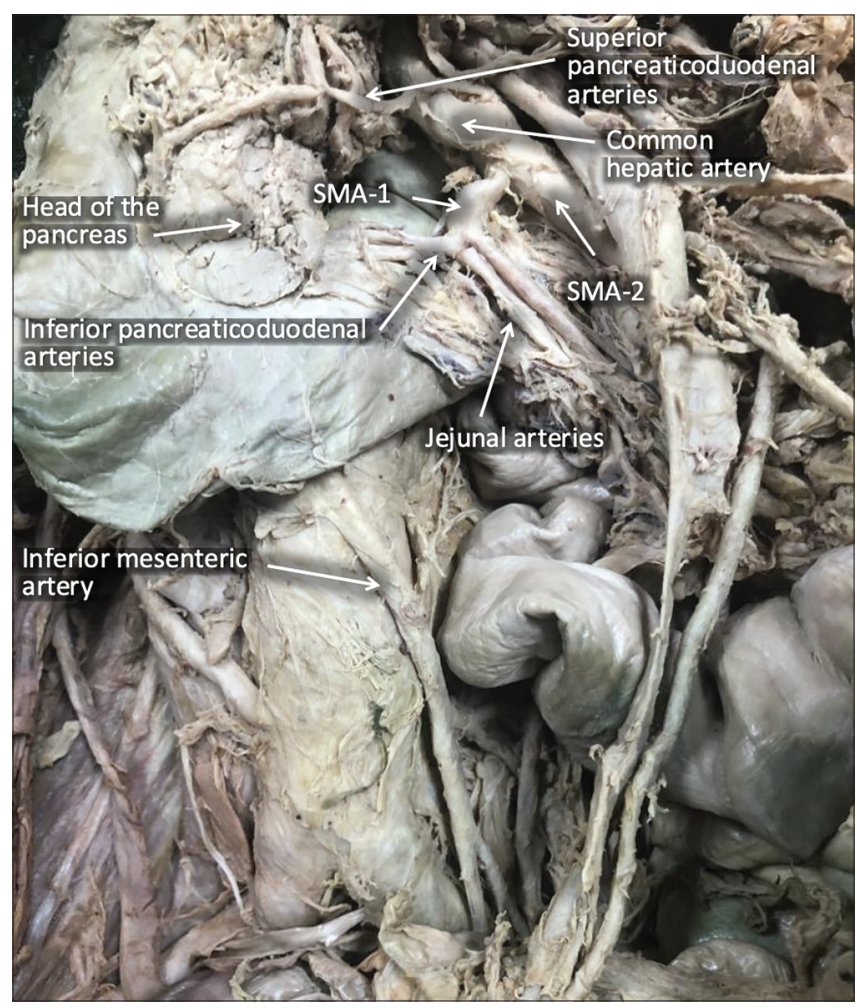

Figure 2: Following bifurcation of the superior mesenteric artery, the common hepatic artery branches from SMA-2

In addition, this case also featured an abnormality in the appearance of the superior pancreaticoduodenal 
arteries and the subsequent anterior and posterior divisions branching from SMA-2, instead of its "normal" anatomical pattern branching from the CT, the anterior division of the superior pancreaticoduodenal artery instead loops around the head of the pancreas before forming an anastomosis with the anterior division of the inferior pancreaticoduodenal artery that stemmed from SMA-1. However, the posterior division of the superior pancreaticoduodenal artery looped around the body of the pancreas and formed an anastomosis with the posterior division of the inferior pancreaticoduodenal artery.

\section{Unique portocaval system communication}

Moving with the dissection to the left side of the abdomen, the portal system revealed an inferior mesenteric vein (IMV) anomaly. Normally, the IMV has three branches: Left colic vein, superior rectal vein, and sigmoid colon vein [10]. The inferior mesenteric artery (IMA) in this case was discovered to have only two of the commonly found branches: The left colic vein and superior rectal vein. In proceeding with the dissection, the left upper posterior abdominal wall revealed LRV tributaries anomaly. The dissection exhibited the LRV with the left testicular vein (LTV) following their normal anatomical path (Figure 3). On further investigation, the LTV displayed an unusual anastomosis with a deviant vein draining closer to the hilum of the left kidney on the LRV (Figure 3). Following the vessel to its origin, the abnormal vein was seen to be coming from the sigmoid colon. Further investigation of this anomaly revealed no other veins branching from the sigmoid colon. Thus, we

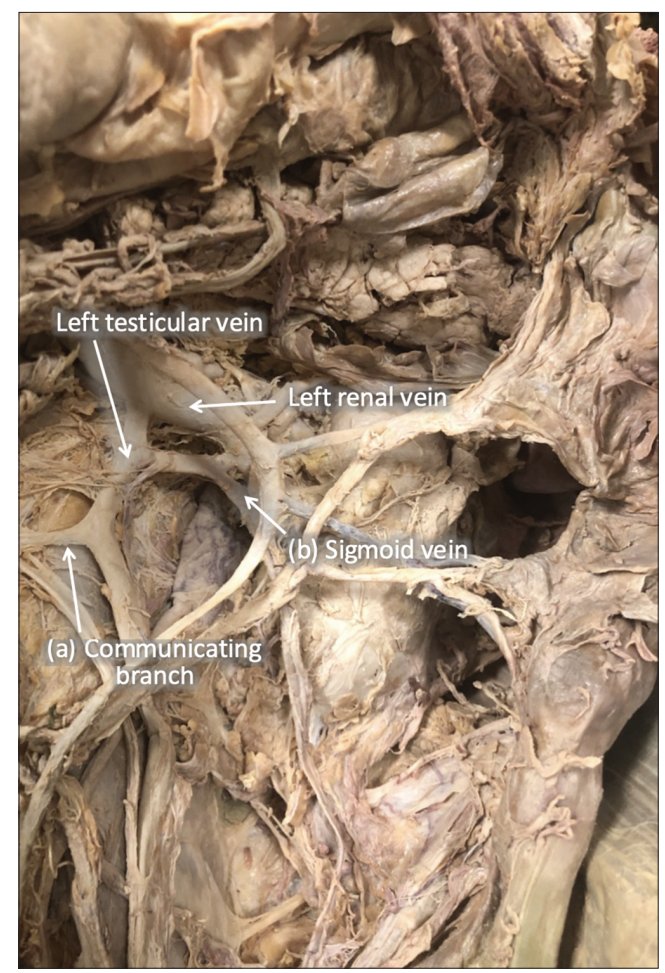

Figure 3: (a) Communicating branch between the Left Testicular vein and Superior Mesenteric vein. (b) Sigmoid vein draining to the Left Renal vein concluded the deviant vein was indeed the sigmoid colon vein. The sigmoid colon vein normally drains in the IMV, a branch of the splenic vein that, in succession, merges with the superior mesenteric vein (SMV), uniting into the portal vein. Another abnormality was observed in the process of dissection of this region: A branch communicating with the SMV. Usually, the LTV stands alone, draining only the left testis with no other branches coming from it

\section{Abnormal variations of renal vasculature}

Moving to the right side, normally, the main RA arises from the abdominal aorta around the level of the L1-L2 vertebrae, located below the SMA [11]. The main $\mathrm{RV}$, however, lies anterior to the RA at the renal hilum and drains into the inferior vena cava [12]. During the dissection of the cadaver, we found that he presented two RA in the right kidney instead of what is normally found. One of them appeared at the normal anatomical L1-L2 level, while the additional RA appeared to come out abnormally from the abdominal aorta around the level of L4. The occurrence of two renal arteries is less common in the right kidney (37.5\%) than in the left kidney (53.6\%) [11]. Interestingly, the renal venous system of the right kidney presented the same abnormalities, we found in the arterial system. The cadaver presented the main RV arising from the intervertebral L1-L2 level and another RV around the L4 level. In this case, venous abnormalities, such as multiple RV, are more common in the right kidney than the left [12] (Figure 4). Although our cadaver presented these abnormalities (Table 1), it does not seem that it was detrimental to his health since he still lived a long life and his cause of death was not related to any vascular and/or renal conditions.

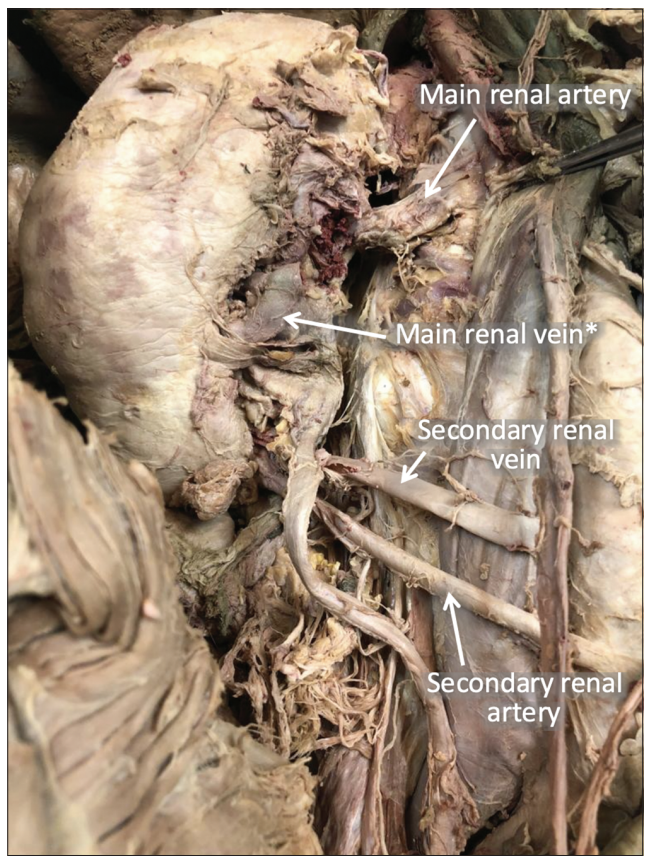

Figure 4: Right renal vasculature. In addition to the main blood vessels, the cadaver presented secondary blood vessels appearing around the level of the L4 vertebrae. "The main renal vein was cut during dissection. 
Table 1: Normal abdominal aorta and inferior vena cava branches versus case report findings

\begin{tabular}{llll}
\hline Vertebral levels & Branches of aorta & Branches of IVC \\
\hline T8 & Normal & Case report & Normal \\
\hline T9-11 & & Inf. phrenic vein hepatic vein \\
T12 & Inferior phrenic a. & Celiac trunk & \\
& Celiac trunk & Inferior phrenic (as a branch of the & \\
L1 & Superior suprarenal a. & Celiac trunk not aorta) & \\
& SMA a. & SMA-1 a. & Renal veins \\
& Inf. Phrenic a. & SMA-2 a. & Right suprarenal v. \\
L2 & Renal a. & Main renal a. & R. gonadal v. \\
L3 & Gonadal a. & Gonadal a. & Renal veins \\
L4 & Inf. Mesenteric a. & Inf. Mesenteric a. & R. gonadal v. \\
& Common iliac a. (bifurcation) & (Additional) right inferior polar renal a. & \\
\hline
\end{tabular}

\section{Discussion}

Primum non nocere, a Latin dictum meaning "first do no harm," has been a governing principle in medical practice since ancient times. As time progressed, medical advancements have incorporated a continuously growing sector of invasive medical procedures for diagnosis, monitoring, and treatment. The invasive nature of these procedures, however, carries a high possibility of harm due to iatrogenic vascular errors (IVEs). A comprehensive study on IVEs conducted in Sweden revealed that about 33\% of IVEs involve vessels in the abdominal region, with $41 \%$ of IVEs considered avoidable [13]. In addition, the lethal risk was calculated to be $4.9 \%$ more common in patients who suffered an IVE [13], with interventional radiology having the highest reported number of IVEs followed closely by general surgery [13]. Hence, proper understanding and knowledge of vascular anatomical variations play a significant role in eliminating iatrogenic errors, which ultimately contribute to the burden of disease and mortality.

Variations in vascular supply to the foregut and midgut are quite common. Using Michel's classification system for hepato-arteries, a Type IX variation is seen in which the common hepatic artery branches from the SMA instead of the CT [7]. Variations in the hepatic-celio-artery are important to note, as they may indicate the presence of variations in renal vessels like those seen in this dissection and in other studies [8]. The multiple abnormalities observed in the midgut vascular supply not only in this case report but also in intraoperative studies demonstrate common hepatic artery aberrations course similarly with gastroduodenal arteries [9] and are noteworthy for certain surgical settings.

\section{arterial system \\ Embryonic development of the abdominal}

During human embryonic development, vascular formation occurs through highly dynamic and complex coordination of two distinct mechanisms vasculogenesis and angiogenesis [14]. In the process of vasculogenesis, mesenchymal precursor cells called hemangioblasts, located in the extraembryonic yolk sac, cluster together, forming blood islands as early as the $17^{\text {th }}$ day of embryogenesis, which develop into capillary tubes possessing a lumen [15]

Angiogenesis, on the other hand, is responsible for the remodeling and expansion of these preformed vessels through two remodeling processes endothelial sprouting and intussusceptive angiogenesis. Endothelial sprouting is a more invasive process that is under the heavy influence of growth factors such as VEGF and specialized tip cells which possess filopodia (cytoplasmic projections) and growth factor receptors, allowing them to migrate to the surrounding mesenchyme and regulate capillary branching and development of new arteries and vessels [16]. Intussusceptive (nonsprouting) angiogenesis involves the longitudinal splitting of a vessel (in a zipper-like fashion) into two vessels through the formation of cylindrical structures that extend through the lumen of the capillaries, called intussusceptive pillars. Although this mechanism is not fully understood, it is suggested that it can influence the branching angle of a bifurcating vessel, duplicate a parent vessel, and trim an inefficient vessel [17]. We suggest that possible defects in this pathway or unnecessary intussusceptive pillar formation can also contribute to vascular variations, especially those involving the existence of duplicate arteries and veins such as the presence of a dual SMA and the presence of a duplicated right renal artery (RRA) in this case presentation.

Three arterial branches supply distinct sections of the embryo: The ventral intersegmental artery will supply the gut tube and its associated organs; the lateral intersegmental artery will supply the retroperitoneal organs; and finally, the dorsal intersegmental artery will supply the muscle tissue of the back, limbs, and trunk. For this paper, we will only focus on the ventral and lateral intersegmental branches, which can be associated with the vascular variations, present in this case report. The paired primitive dorsal aortae are located dorsally to the developing gut tube, with the ventral intersegmental arterial branches surrounding the omphalomesenteric duct (vitelline duct) (Table 2). The primitive vessels

Table 2: Embryonic dorsal aorta branches and adult derivatives

\begin{tabular}{ll}
\hline Embryonic & Adult \\
\hline $\begin{array}{l}\text { Ventral segmental arteries - } \\
\text { vitelline arteries umbilical artery? }\end{array}$ & Celiac trunk, SMA, IMA \\
$\begin{array}{l}\text { Lateral segmental arteries } \\
\text { Posterolateral segmental arteries }\end{array}$ & $\begin{array}{l}\text { Renal a., Suprarenal a., gonadal a. } \\
\text { Arterial supply to muscles of the upper and lower } \\
\text { limb, trunk, back }\end{array}$ \\
\hline SMA: Superior mesenteric artery, IMA: Inferior mesenteric artery.
\end{tabular}


either fuse or degenerate, giving rise to three major abdominal arterial branches from cranially to caudally: The CT, which supplies the foregut; the SMA which supplies the midgut; and the IMA which supplies the hindgut (Tables 2 and 3). Failure of ventral segmental arteries and omphalomesenteric arteries to fuse or pair can lead to vascular variations and abnormalities such as the ones present in our case report [18].

Table 3: Embryonic IVC branches and adult derivatives

\begin{tabular}{ll}
\hline Embryonic & Adult \\
\hline Vitelline veins & Portal v., Hepatic v., ductus venosus, Splenic v., SMV, IMV \\
Umbilical veins & Hepatic sinusoids, ligamentum teres \\
Cardinal veins & \\
Anterior & SVC, Internal Jugular v., \\
Posterior & Common iliac v. \\
Subcardinal & Renal v., gonadal v. \\
Supracardinal & Intercostal v., hemiazygos v., azygos v. \\
\hline IVC: Inferior vena cava, SMV: Superior mesenteric vein, IMV: Inferior mesenteric vein.
\end{tabular}

Renal vascular anatomical variations in the form of multiple renal arteries and veins termed as aberrant, supernumerary, or accessory, are estimated to occur in $20-50 \%$ of the population, which makes this variation more common than in any other organ [19]. Classically, each terminally developed kidney is supplied by a single RA, which is a branch of a single lateral segmental artery arising from the abdominal aorta at the vertebral level between L1 and L2. In a study of arterial patterns of 200 renal pedicles, it was estimated that only about $38.8 \%$ of RRAs arose from the $L 1$ to $L 2$ vertebral level and only $35.7 \%$ of the left renal arteries arose from the same level. Nonetheless, the L1-L2 level remains the most frequent site of RA branching [19]. In the same study, it was estimated that $61.5 \%$ of the pedicles presented with additional renal arteries. Multiple renal arteries were observed to possess different patterns such as 2-4 hilar arteries and usually 1-2 superior or inferior pole arteries. More specifically, it was calculated that an additional inferior polar RA was observed in $3.57 \%$ of cases in the right kidney and $2.9 \%$ in the left kidney [19]. This result coincides with our case presentation finding of an additional RA possessing an inferior polar pattern in the right kidney. Another study on renal patterns of 100 healthy kidney donors also supported that renal kidney variation is extremely frequent. It was observed that $51 \%$ of the 100 kidney donors had some type of renal arterial variation, with the most common being an additional RA [20].

$\mathrm{RV}$ variations are also frequent, especially in individuals who already possess a RA variation. In a study performed by Zhu et al., attempting to estimate the incidence of $\mathrm{RV}$ variations in a sample size of 1452 individuals, it was observed that $24.7 \%$ had an $\mathrm{RV}$ variation with $7.1 \%$ involving the left $\mathrm{RV}$ and $19.2 \%$ involving the right RV [10]. It is important to note the higher frequency of variations in the right $\mathrm{RV}$ compared to the LRV.

During nephrogenesis, transition from the mesonephric structures to the metanephric structures, there is a high probability of renal vascular variations to occur, mostly through the persistence or nonobliteration of a mesonephric artery. At the same time, because the pelvis of the embryo is relatively small in size and organs and their vascular supplies are in close proximity with each other, it is suggested that the metanephros also receives arterial branches from the common iliac arteries in addition to the branches from the aorta, which later degenerate as the kidneys ascend to allow the existence of only one definitive $\mathrm{RA}$. A defect in the degradation or persistence of these branches, however, can also contribute to multiple renal arteries [21].

\section{Genetic involvement in vasculogenesis and angiogenesis}

The genetics of vascular development are complex and are currently under active investigation both in animal studies and in the deep whole-genome analysis. The major genes implicated during angiogenesis include PI3k/Akt [22], TGF-beta [23], TIE2/TEK [24], and TIE2/ TEK [25]. Among the gene mutations, implicated in vascular anomalies are those having an effect on endothelial proliferation, migration, attachment, stem cell differentiation, as well as survival [26]. However, as with the case presented here, a circulatory system with multiple vascular abnormalities with the anomalies seemingly confined to the abdomen, the genetic basis of errors of vasculogenesis raises the question as to why these abnormalities are not generalized in the body? The answer lies in the concept of epigenetics and mosaicism: The genetic defects are found only in a small subclass of cells within the area where the anomaly has occurred [27]. The local effects of abnormal angiogenesis-related genes are likely enhanced by cytokines such as TGFbeta and TNF-alpha that act in a paracrine manner to stimulate vascularization [28].

\section{Possible clinical and surgical implications of these vascular variations}

In recent years, there has been much interest in the pre-operative mapping of a patient's vasculature to account for abnormalities and prepare for any complications relative to them. One group considers it essential before a right colon resection to utilize 3D reconstructed anatomy derived from pre-operative CT scans, which enables the surgical team to visualize vessel loops with origins and confluences of aberrant vessels to be able to manage incidental bleeding promptly [29]. In this case, in particular, the presence of an additional right inferior polar RA at the level of $L 4$ would be beneficial to be aware of prior paraaortic lymphadenectomy, for instance, an operation that has therapeutic benefit for patients with advanced endometrial cancer and which is done in close proximity with major vessels and already has a high risk of hemorrhage [30]. The double SMA could provide challenges in the treatment 
of SMA syndrome - where the SMA compresses the $3^{\text {rd }}$ part of the duodenum - and which is accomplished by laparoscopic duodenojejunostomy. The degree of the angle of the SMA branching off the aorta is normally 45 , but a reduction in that angle to below 25 could predispose to duodenal compression, as could a low origin [31] - thus it is conceivable that an additional SMA can contribute to the development of this condition. In addition to intraoperative hemorrhagic complications of abnormal $\mathrm{Gl}$ vasculature, damage to unrecognized vessels has been linked to diaphragmatic necrosis (possible in this case with right IPA a branch of the CT instead of the aorta), thrombosis of the accessory artery, vasculopathy, and ischemic necrosis [32]. There is a strong need to grow basic sciences and pre-operative imaging study capabilities of vascular abnormalities to reduce IVE during invasive procedures.

\section{Conclusion}

The published data, as reviewed in this manuscript, indicated that vascular variations in the $\mathrm{GI}$ system are not an uncommon finding. However, the concomitant involvement of the various arterial and venous variations found in our cadaveric specimen demonstrates a unique case of tremendous anatomical, functional, and surgical importance. In this report, these vascular variations were discussed extensively in an anatomical, developmental, and clinical context. Collectively, this case illustrated the need for a deeper understanding of the $\mathrm{Gl}$ vascular architecture and the associated variations to ensure a positive patient outcome and reduce iatrogenic errors and complications during procedures. In addition, we suggested that expanding the scope of pre-operative imaging along with anatomical knowledge could have a significant impact on identifying variations and eliminating the risk for iatrogenic errors and complications.

\section{References}

1. Douard R, Chevallier JM, Delmas V, Cugnenc PH. Clinical interest of digestive arterial trunk anastomosis. Surg Radiol Anat. 2006;28(3):219-27. https://doi.org/10.1007/s00276-006-0098-8 PMid:16547602

2. Panagouli E, Venieratos D, Lolis E, Skandalakis P. Variations in the anatomy of the celiac trunk: A systematic review and clinical implications. Ann Anat. 2013;195(6):501-51. https://doi. org/10.1016/j.aanat.2013.06.003 PMid:23972701

3. Mahajan A, Tiwari S, Mishra S. A unique conglomeration of variations in the celiac, hepatic, and superior mesenteric artery: A clinico-embryological perspective. Int J Appl Basic Med Res. 2018;8(4):256-8.

\section{PMid:30598915}

4. Fakoya AO, Aguinaldo E, Velasco-Nieves NM, Vandeveer ZT, Morales-Marietti N, Mathew S, et al. A unique communicating arterial branch between the celiac trunk and the superior mesenteric artery: A case report. Open Access Maced J Med Sci. 2019;7(13):2138-41. https://doi.org/10.3889/oamjms.2019.562 PMid:31456840

5. Hazirolan T, Öz M, Türkbey B, Karaosmanoglu AD, Oguz BS CanyigitM. CT angiography of the renal arteries and veins: Normal anatomy and variants. Diagn Interv Radiol. 2011;17(1):67-73. https://doi.org/10.4261/1305-3825.dir.2902-09.1 PMid:20151356

6. Olewnik $Ł$, Wysiadecki G, Polguj M, Topol M. A rare anastomosis between the common hepatic artery and the superior mesenteric artery: A case report. Surg Radiol Anat. 2017;39(10):1175-9. https://doi.org/10.1007/s00276-017-1859-2

PMid:28432408

7. da Silveira LA, Cassiano FB, Sassoli VP. Arterial diameter of the celiac trunk and its branches: Anatomical study. Acta Cir Bras. 2009;24(1):43-7. https://doi.org/10.1590/ s0102-86502009000100009

PMid:19169541

8. Winter TC, Nghiem HV, Freeny PC, Hommeyer SC, Mack LA Hepatic arterial anatomy: Demonstration of normal supply and vascular variants with three-dimensional $\mathrm{CT}$ angiography. Radiographics. 1995;15(4):771-80. https://doi.org/10.1148/ radiographics.15.4.7569128

PMid:7569128

9. Shaikh H, Khorasani-Zadeh A. Abdomen and Pelvis, Superior Mesenteric Artery. Treasure Island, FL: StatPearls; 2019.

10. Horton KM, Fishman EK. Volume-rendered $3 D C T$ of the mesenteric vasculature: Normal anatomy, anatomic variants, and pathologic conditions. Radiographics. 2002;22(1):161-72. https://doi.org/10.1148/radiographics.22.1.g02ja30161 PMid:11796905

11. Gulas E, Wysiadecki G, Szymański J, Majos A, Stefańczyk L, Topol M, et al. Morphological and clinical aspects of the occurrence of accessory (multiple) renal arteries. Arch Med Sci. 2018;14(2):442-53. https://doi.org/10.5114/aoms.2015.55203 PMid:29593819

12. Al-Katib S, Shetty M, Jafri SM, Jafri SZ. Radiologic assessment of native renal vasculature: A multimodality review. Radiographics. 2017;37(1):136-56. https://doi.org/10.1148/rg.2017160060

13. Rudström H. latrogenic Vascular Injuries; 2013. Available from: http://www.uu.diva-portal.org/smash/get/diva2:605251/ FULLTEXT01.[Last accessed on 2020 Feb 03]

14. Patan S. Vasculogenesis and angiogenesis. Cancer Treat Res. 2004;117:3-32.

PMid: 15015550

15. Singh R, Soman-Faulkner K, Sugumar K. Embryology, Hematopoiesis. Treasure Island, FL: StatPearls; 2019.

16. le Noble F, Fleury V, Pries A, Corvol P, Eichmann A, Reneman RS. Control of arterial branching morphogenesis in embryogenesis: Go with the flow. Cardiovasc Res. 2005;65(3):619-28. https:/l doi.org/10.1016/j.cardiores.2004.09.018 PMid:15664388

17. Fakoya A. New delivery systems of stem cells for vascular regeneration in ischemia. Front Cardiovasc Med. 2017;4:7. https://doi.org/10.3389/fcvm.2017.00007 PMid:28286751

18. Noussios G, Dimitriou I, Chatzis I, Katsourakis A. The main anatomic variations of the hepatic artery and their importance in surgical practice: A review of the literature. $\mathrm{J}$ Clin Med Res. 2017;9(4):248-52. https://doi.org/10.14740/jocmr2902w 


\section{PMid:28270883}

19. Palmieri BJ, Petroianu A, Silva LC, Andrade LM, Albert LR. Study of arterial pattern of 200 renal pedicle through angiotomography. Rev Col Bras Cir. 2011;38(2):116-12. PMid:21710050

20. Munnusamy K, Kasirajan SP, Gurusamy K, Raghunath G, Bolshetty SL, Chakrabarti S, et al. Variations in branching pattern of renal artery in kidney donors using CT angiography. J Clin Diagn Res. 2006;10(3):AC01-3. https://doi.org/10.7860/ jcdr/2016/16690.7342

PMid:27134847

21. Isogai S, Horiguchi M, Hitomi J. The para-aortic ridge plays a key role in the formation of the renal: Adrenal and gonadal vascular systems. J Anat. 2010;216:656-70. https://doi. org/10.1111/j.1469-7580.2010.01230.x PMid:20579173

22. Taha KM, Alsharif MH, Elamin AY. Variation in morphology and branching pattern of superior mesenteric artery. Folia Morphol. 2017;76(3):532-5. https://doi.org/10.5603/fm.a2017.0001 PMid:28150273

23. Hamada K, Sasaki T, Koni PA, Natsui M, Kishimoto $H$ Sasaki J, et al. The PTEN/PI3K pathway governs normal vascular development and tumor angiogenesis. Genes Dev. 2005;19:2054-65. https://doi.org/10.1101/gad.1308805 PMid:16107612

24. Queisser A, Boon LM, Vikkula M. Molecular genetics of vascular malformations. In: eLS. Hoboken: John Wiley \& Sons, Ltd.; 2020. https://doi.org/10.1002/9780470015902.a0021459.pub2

25. Frigerio A, Stevenson DA, Grimmer JF. The genetics of vascular anomalies. Curr Opin Otolaryngol Head Neck Surg. 2012;20(6):527-32. https://doi.org/10.1097/ moo.0b013e3283587415

PMid:22913934
26. Shibuya M. Vascular endothelial growth factor (VEGF) and its receptor (VEGFR) signaling in angiogenesis: A crucial target for anti- and pro-angiogenic therapies. Genes Cancer. 2011;2(12):1097-105. https://doi org/10.1177/1947601911423031

PMid:22866201

27. Ucuzian AA, Gassman AA, East AT, Greisler HP. Molecular mediators of angiogenesis. J Burn Care Res. 2010;31(1):15875. https://doi.org/10.1097/bcr.0b013e3181c7ed82 PMid:20061852

28. Zuniga-Castillo M, Teng CL, Joyce MC. Genetics of vascular malformation and therapeutic implications. Curr Opin Pediatr. 2019;31(4):498-508.

PMid:31246627

29. Nesgaard JM, Stimec BV, Ignjatovic D. Is tracing vessels to the origin in right colectomy really impossible? Dis Colon Rectum. 2017;60(8):607-8. https://doi.org/10.1097/ dcr.0000000000000866 PMid:28682977

30. Kato K, Tate S, Nishikimi K, Shozu M. Surgical anatomy of the common iliac veins during para-aortic and pelvic lymphadenectomy for gynecologic cancer. J Gynecol Oncol. 2014;25(1):64-9. https://doi.org/10.3802/jgo.2014.25.1.64 PMid:24459583

31. Kingham TP, Shen R, Ren C. Laparoscopic treatment of superior mesenteric artery syndrome. JSLS. 2004;8(4):376-9

PMid:15554285

32. Randjelovic DT, Filipovic RB, Bilanovic LD, Stanisavljevic SN Perigastric vascular abnormalities and the impact on esophagogastrectomy. Dis Esophagus . 2007;20(5):390-8. https://doi.org/10.1111/j.1442-2050.2007.00633.x

PMid:17760652 